\title{
Hemidiaphragm plication after repair of congenital heart defects in children: Quantitative return of diaphragm function over time
}

\author{
Craig J. Baker, MD, ${ }^{a, b}$ Valy Boulom, MS, Brian L. Reemtsen, MD, ${ }^{a, b}$ Robert C. Rollins, MD, ${ }^{c}$ \\ Vaughn A. Starnes, MD, a,b and Winfield J. Wells, MD ${ }^{a, b}$
}

Objective: Phrenic nerve injury resulting in hemidiaphragm paresis leads to morbidity in children undergoing repair of congenital heart defects. Previous studies have documented short-term benefits of diaphragm plication, but little is known about the return of diaphragm function.

Methods: We reviewed 46 consecutive patients undergoing hemidiaphragm plication after repair of congenital heart defects. The function of plicated diaphragms was measured at follow-up fluoroscopy using excursion of the unplicated side as a control.

Results: The median age at the procedure resulting in phrenic nerve injury was 6.4 months (0-62 months). Among the 46 patients, 29 (63\%) and 17 (37\%) had repair for single and 2-ventricle defects, respectively. Hemidiaphragm paresis occurred on the left side in 32 patients (70\%). Phrenic nerve injury was documented at a median of 8 days (1-84 days) after operation. The median time from diagnosis to plication was 2 days (0-21 days). Five patients required prolonged ventilation after plication. One patient died 10 weeks later, and 4 patients required tracheostomy. The remaining 41 patients were extubated within 2 days (0-19 days). In 17 patients, fluoroscopy assessing diaphragm motion was performed at a mean interval of 16.4 months after plication. Excursion of the plicated diaphragm was $77 \%$ of the contralateral side. There was a trend toward improved function over time.

Conclusions: Hemidiaphragm paresis results in significant morbidity after repair of congenital heart defects. Early diagnosis and plication result in timely extubation. The plicated diaphragm demonstrates return of function that may improve over time. This is the first study to numerically quantitate the degree of diaphragm recovery.

From the Department of Cardiothoracic Surgery, University of Southern California Keck School of Medicine ${ }^{\mathrm{a}}$ and Divisions of Cardiothoracic Surgery ${ }^{\mathrm{b}}$ and Cardiology, Children's Hospital Los Angeles, ${ }^{\mathrm{b}}$ Los Angeles, Calif.

Received for publication July 6, 2007; revisions received Aug 16, 2007; accepted for publication Sept 20, 2007.

Address for reprints: Craig J. Baker, MD, Department of Cardiothoracic Surgery, 1520 San Pablo Street, Suite 4300, Los Angeles, CA 90033 (E-mail: cbaker@ surgery.usc.edu).

J Thorac Cardiovasc Surg 2008;135:56-61 $0022-5223 / \$ 34.00$

Copyright $\odot 2008$ by The American Association for Thoracic Surgery

doi:10.1016/j.jtcvs.2007.09.031
$\mathrm{D}$ iaphragm paresis (DP) is a complication of operations for congenital heart disease, resulting in significant morbidity. The most common cause of DP is operative trauma to the phrenic nerve, with an incidence of $0.3 \%$ to $12.8 \%$. ${ }^{1}$ This complication has been associated with operations spanning the spectrum of congenital heart disease. ${ }^{2-9}$ Operative trauma to the phrenic nerve may occur directly during dissection, ${ }^{10}$ be related to thermal injury (iced saline or cautery current), or occur during placement of central lines.

Inability to wean from a ventilator after surgery is often the first sign of DP. After extubation, respiratory distress, atelectasis, and recurrent pneumonia may suggest the diagnosis. ${ }^{1}$ These findings are often substantiated by an elevated diaphragm on chest $\mathrm{x}$-ray. Confirmatory results are obtained by ultrasound and/or fluoroscopy. Infants and younger children, in contrast with older children, are especially intolerant of phrenic nerve injury because of their 1) underdeveloped intercostal musculature, 2) greater chest wall compliance, 3) horizontal rib cage orientation because of increased supine positioning, and 4) mediastinal hypermobility. ${ }^{11}$

Although some infants and children may recover without intervention, many require diaphragm plication to be weaned from ventilatory support in a timely manner. 


\section{Abbreviation and Acronym}

$\mathrm{DP}=$ diaphragm paresis

Diaphragm plication has been used since 1954 for the treatment of hemidiaphragm paresis. ${ }^{2,8}$ It is now the standard treatment of DP for children aged less than 1 year, yet the long-term outcome is unclear. Published reports have included small numbers of study subjects; however, there is little information on the recovery of diaphragm function.

No report to date has objectively quantitated the degree of recovery of diaphragm function. In this retrospective study, we sought to determine the fate of the plicated diaphragm after phrenic nerve injury.

\section{Materials and Methods}

This study was approved by the institutional review board at the Children's Hospital Los Angeles.

\section{Patient Data}

We performed a retrospective review inclusive of all patients who underwent diaphragm plication from April of 1996 to April of 2005 at the Children's Hospital Los Angeles in California. Diaphragm paralysis was suspected if a postoperative chest x-ray demonstrated an elevated hemidiaphragm and the patient had difficulty weaning from the ventilator. The chest $\mathrm{x}$-ray was compared with the preoperative chest $\mathrm{x}$-ray to verify the change in diaphragm position. This diagnosis was then confirmed by fluoroscopy. In patients undergoing fluoroscopy while still intubated, the examination was performed during a period of spontaneous breathing without the assistance of pressure support. Chart review extracted information on demographics, cardiac morphology, the procedural factors related to the operation for repair of congenital heart disease, and the early postoperative course, especially related to the need for assisted ventilation. Intermediate-term follow-up was accomplished by direct contact whenever possible and otherwise by correspondence with the patient's regular physician.

\section{Diaphragm Plication}

Our method of plication is performed in accordance with the technique described by Schwartz and Filler ${ }^{12}$ using multiple parallel rows of interrupted 2-0 pledgetted monofilament sutures placed in an anterior-to-posterior orientation. The plication sutures are taken primarily in the membranous area of the diaphragm with the intention of bringing the diaphragm down to a point that is 1 to 2 interspaces below its usual level. We performed all of our diaphragm plications through a thoracotomy at the seventh intercostal space.

\section{Diaphragm Function}

In a subset of the patients, a late fluoroscopic study of the diaphragms was available for analysis that included the degree of plicated hemidiaphragm movement compared with the patient's normal hemidiaphragm. Fluoroscopy was viewed in anteroposterior or lateral projections using the dome of the diaphragm as a standardized point of reference. The position of the plicated diaphragm was marked at the end of expiration using real-time cine fluoroscopy. The movement of the diaphragm was followed during inspiration, and the position at the end of inspiration was marked. Excursion of the plicated hemidiaphragm was measured in millimeters at the point of maximal inspiration and compared with the excursion of the normal, nonplicated diaphragm at the same location.

\section{Results \\ Patient Demographics}

A total of 46 patients ( 22 female and 24 male) with a median age of 6.81 months (range 0.27-63 months) underwent diaphragm plication after a congenital cardiac procedure between April of 1996 and December of 2005. The diagnoses and operations resulting in phrenic nerve injury are listed in Table 1 . The majority of patients $(63 \%)$ underwent repair for single-ventricle heart disease with hypoplastic left heart syndrome as the most common single-ventricle diagnosis (59\%). Among patients with single-ventricle repairs, phrenic nerve injury occurred at the time of the initial operation in 9 $(31 \%)$ versus a second or subsequent staged procedure in 20

TABLE 1. Open procedures resulting in phrenic nerve paresis

\begin{tabular}{|c|c|c|c|}
\hline \multirow[b]{2}{*}{ Principle diagnosis } & \multirow[b]{2}{*}{ No. } & \multicolumn{2}{|c|}{ Operation resulting in PNP } \\
\hline & & Procedure & No. \\
\hline \multirow{4}{*}{$\begin{array}{l}\text { Single-ventricle diagnosis } \\
\text { HLHS }\end{array}$} & 29 & & \\
\hline & 17 & Norwood & 8 \\
\hline & & BDG & 7 \\
\hline & & Fontan & 2 \\
\hline Other single ventricle & 12 & & \\
\hline TGA, tricuspid atresia & 3 & DKS & 1 \\
\hline Unbalanced AVCD & 2 & $\mathrm{BDG}$ & 10 \\
\hline LTGA, PA & 1 & Fontan & 1 \\
\hline LTGA, DORV & 2 & & \\
\hline LTGA, Epstein's & 1 & & \\
\hline TGA, hypoplastic RV & 1 & & \\
\hline DTGA, PS & 1 & & \\
\hline Pulmonary atresia & 1 & & \\
\hline Double-ventricle diagnosis & 17 & & \\
\hline TAPVR & 7 & Complete repair & 7 \\
\hline IAA & 3 & Complete repair & 3 \\
\hline TGA & 3 & ASO & 3 \\
\hline Hypoplastic arch, AS & 1 & Ross, arch repair & 1 \\
\hline ALCAPA & 1 & Repair & 1 \\
\hline TOF, pulmonary atresia & 1 & Rastelli repair & 1 \\
\hline Epstein's & 1 & Repair of Epstein & 1 \\
\hline
\end{tabular}

PNP, Phrenic nerve paralysis; HLHS, hypoplastic left heart syndrome; TGA, transposition of the great arteries; $R V$, right ventricle; $A V C D$, atrial-ventricular canal defect; $P A$, pulmonary atresia; $D O R V$, double outlet right ventricle; $P S$, pulmonary stenosis; TAPVR, total anomalous pulmonary venous return; $I A A$, interrupted aortic arch; $A S$, aortic stenosis; ALCAPA, anomalous left coronary artery from pulmonary artery; TOF, tetralogy of Fallot; $B D G$, bidirectional Glenn; DKS, Damus-Kaye-Stansel; $A S O$, arterial switch operation; LTGA, L-transposition of the great arteries; DTGA, D-transposition of the great arteries. 
(69\%). The overall incidence of phrenic nerve injury requiring plication was $2.9 \%$ after a Norwood type procedure, $3.5 \%$ after a bidirectional Glenn procedure, and $0.75 \%$ after a Fontan procedure. For those with a single-ventricle defect, the most common operation resulting in phrenic nerve injury was a bidirectional Glenn procedure (59\%). Of those patients undergoing 2-ventricle repairs, the most common operation resulting in DP was correction of total anomalous pulmonary venous return $(7 / 17$ or $41 \%)$. The overall incidence of DP after repair of total anomalous pulmonary venous return was $3.5 \%$. Hemidiaphragm paresis occurred on the left in 32 patients $(70 \%)$.

\section{Clinical Course}

The median duration from the time of phrenic nerve injury to the diagnosis of DP was 8 days (range 1-84 days). The median time between the diagnosis of DP and diaphragm plication was 2 days (range 0-21 days). Five patients had prolonged ventilatory support after plication, including 1 who died of necrotizing enterocolitis and 4 who required a tracheostomy for ongoing respiratory insufficiency. Among the remaining 41 patients, the median time to extubation after plication was 2 days (range 0-19 days) (Table 2). An example of a chest x-ray obtained before and after plication is depicted in Figure 1.

\section{Diaphragm Function}

A follow-up fluoroscopy examination was performed on 17 of the 46 patients at variable times after diaphragm plication (mean 16.4 months), as documented in Table 3 . In all but 1 patient, the plicated diaphragm demonstrated return of function. The movement of the plicated diaphragm was measured in millimeters at the point of maximum inspiration and compared with the nonplicated diaphragm. Some 16 of 17 patients had a $33 \%$ or greater return of function, and 8 patients demonstrated plicated diaphragm excursion greater than $75 \%$ of the normal diaphragm (Figure 2). The return of diaphragm function over time is shown in Figure 3. There is a trend toward improved function of the plicated diaphragm over time.

TABLE 2. Summary of patient data $(n=46)$

\begin{tabular}{lc}
\hline \multicolumn{1}{c}{ Parameter } \\
\hline Median age at plication & $6.81 \mathrm{mo}$ \\
Male/female & $24 \mathrm{M} / 22 \mathrm{~F}$ \\
L/R & $32 \mathrm{~L} / 14 \mathrm{R}$ \\
& Median (mean) d \\
Time from injury to diagnosis of PNP & $8(12)$ \\
Time from diagnosis of PNP to plication & $2(3)$ \\
Days intubated before plication & $12(17)$ \\
Days intubated after plication $(\mathrm{n}=41)$ & $2(3)$ \\
\hline
\end{tabular}

PNP, Phrenic nerve paralysis.

\section{Discussion}

Early reports of diaphragm plication demonstrated its success in treating diaphragmatic paralysis in infancy. In 1978, Schwartz and Filler ${ }^{12}$ described their surgical technique of plication and published results on 6 infants. Five of the infants were eventually capable of maintaining adequate ventilation without support. This early report comments that 4 patients had a fluoroscopy 1 month or more postoperatively and notes "appropriate motion" in 2 of the cases. Shoemaker and colleagues ${ }^{4}$ subsequently published results of 7 patients undergoing diaphragm plication after operations for congenital heart disease. Three operative approaches were described with the majority of patients undergoing central plication using mattress sutures creating pleats as described by Schwartz and Filler. $^{12}$ This has been our technique of choice. Diaphragm function was documented by fluoroscopy several months to several years postplication in 3 surviving patients. Both of these early series suggested improved outcomes associated with early plication when compared with previous studies documenting a $20 \%$ to $25 \%$ mortality rate in patients with DP who did not undergo operation.

Phrenic nerve injury was diagnosed in 125 children (1.6\%) undergoing pediatric cardiac surgery in a retrospective study published by Watanabe and colleagues ${ }^{7}$ in 1987 . The most common open procedures resulting in phrenic nerve paralysis were the Mustard procedure (6.7\%) and right ventricular outflow tract reconstruction $(5.6 \%)$. Redo operations either by sternotomy or thoracotomy resulted in almost twice the incidence of phrenic nerve paralysis. Seventy percent of the 125 children in this series had a significant postoperative complication with the majority being attributed to the phrenic nerve injury. Only 12 of the 125 patients from this series underwent diaphragm plication. There was no mortality, and plicated patients were extubated 1 to 6 days after their operation. No long-term follow-up was mentioned for the subset of 12 patients who underwent plication.

In a study addressing the long-term fate of the plicated diaphragm, Stone and colleagues ${ }^{6}$ performed fluoroscopy on 6 of 11 patients from 1 to 7 years after plication. In this study, return of function was defined as any degree of orthograde excursion of the plicated diaphragm. No attempt was made to quantify the movement of the diaphragm, and the exact time from plication to follow-up fluoroscopy was not clearly defined. Kizilcan and colleagues ${ }^{13}$ also reported on the long-term results of diaphragm plication by performing fluoroscopy in 12 patients studied 1.5 years to 11 years after plication. The patient population was limited to individuals with congenital eventration of the diaphragm. The degree of motion was graded qualitatively as satisfactory (5), moderately satisfactory (4), or unsatisfactory (3) when compared with the unplicated diaphragm. van Onna and colleagues ${ }^{3}$ had intermediate-term follow-up available for 11 of 14 patients who underwent diaphragm plication after cardiac surgery. Follow-up for diaphragm function was by ultrasound, 

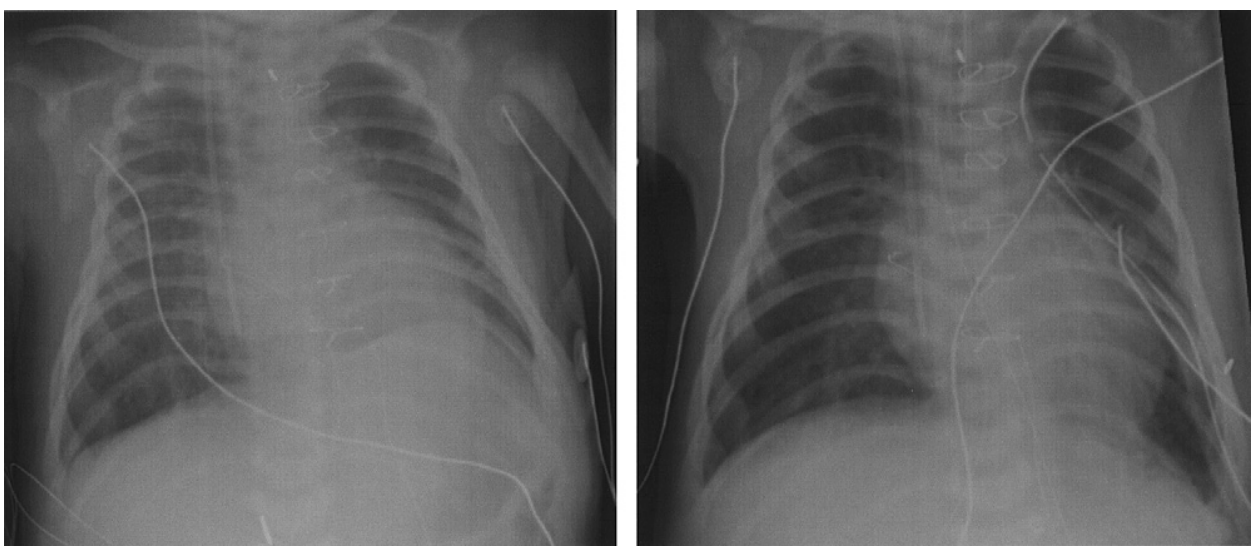

Figure 1. Chest x-rays demonstrating the position of the left hemidiaphragm pre-plication (left) and immediately post-plication (right).

and function was characterized as absent or normal. Only 4 of the 11 patients in this series had return of function.

Tonz and colleagues ${ }^{9}$ studied the clinical outcomes of 25 patients with phrenic nerve injury after pediatric cardiac surgery, noting that no patient older than 2 years required plication whereas 7 of 9 patients aged less than 1 year required a procedure. Their data are consistent with previous reports documenting that infants and young children have greater difficulty with DP when compared with older children. This may be attributed not only to weak intercostals musculature but also to the mobility of the mediastinum, which may impinge on the contralateral lung. Tsugawa and colleagues ${ }^{14}$ examined whether conservative treatment is justified in diaphragmatic eventration. In reviewing their experience with diaphragm plication, they concluded that symptomatic patients who have diaphragmatic eventration should undergo operation immediately with an expected dramatic resolution of their respiratory problems.

de Leeuw and colleagues ${ }^{2}$ studied postcardiac surgery diaphragm paralysis in a population of more than 10,000 children who underwent operation during the 12-year period from 1985 to 1997 . The overall incidence of diaphragm paralysis was $1.6 \%$. The highest prevalence of phrenic injury occurred during operations for systemic venous to pulmonary artery connection, pulmonary arterioplasty, and Blalock-Taussig shunts. A total of 68 of 170 patients with documented diaphragm paralysis underwent diaphragm plication. The authors comment that no standardized protocol was used to recommend plication.

TABLE 3. Diaphragm excursion

\begin{tabular}{|c|c|c|c|c|c|c|}
\hline Patient & Side Paresed & R excursion (cm) & L excursion (cm) & $\begin{array}{c}\text { Ratio of paresed:normal } \\
\text { diaphragm }(\mathrm{cm})\end{array}$ & Quartile & $\begin{array}{l}\text { Time from plication to } \\
\text { fluoroscopy (mo) }\end{array}$ \\
\hline 1 & Left & 1.65 & 1.65 & 1.00 & 4th & 33.7 \\
\hline 2 & Left & 2.40 & 1.30 & 0.54 & $3 r d$ & 6.2 \\
\hline 3 & Left & 0.95 & 0.70 & 0.74 & $3 r d$ & 4.3 \\
\hline 4 & Right & 1.25 & 0.75 & 1.67 & 4th & 20.5 \\
\hline 5 & Left & 2.10 & 1.90 & 0.90 & 4th & 45 \\
\hline 6 & Right & 0.75 & 0.65 & 1.15 & 4th & 12.7 \\
\hline 7 & Left & 1.85 & 1.20 & 0.65 & $3 r d$ & 14.2 \\
\hline 8 & Left & 1.25 & 1.30 & 1.04 & 4th & 30.3 \\
\hline 9 & Left & 1.50 & 0.50 & 0.33 & 2nd & 27.5 \\
\hline 10 & Right & 0.95 & 1.00 & 0.95 & 4th & 4.0 \\
\hline 11 & Left & 2.60 & 1.80 & 0.69 & $3 r d$ & 8.6 \\
\hline 12 & Left & 2.35 & 1.70 & 0.72 & $3 r d$ & 4.4 \\
\hline 13 & Left & 1.80 & 0.0 & 0.00 & $\mathrm{~N} / \mathrm{A}$ & 2.4 \\
\hline 14 & Left & 2.10 & 1.0 & 0.48 & 2nd & 5.3 \\
\hline 15 & Left & 1.60 & 0.70 & 0.44 & 2nd & 21.8 \\
\hline 16 & Right & 1.2 & 1.4 & 0.86 & 4th & 10.8 \\
\hline 17 & Right & 1.4 & 1.4 & 1.0 & 4th & 28.0 \\
\hline
\end{tabular}

$N / A$, Not available. 


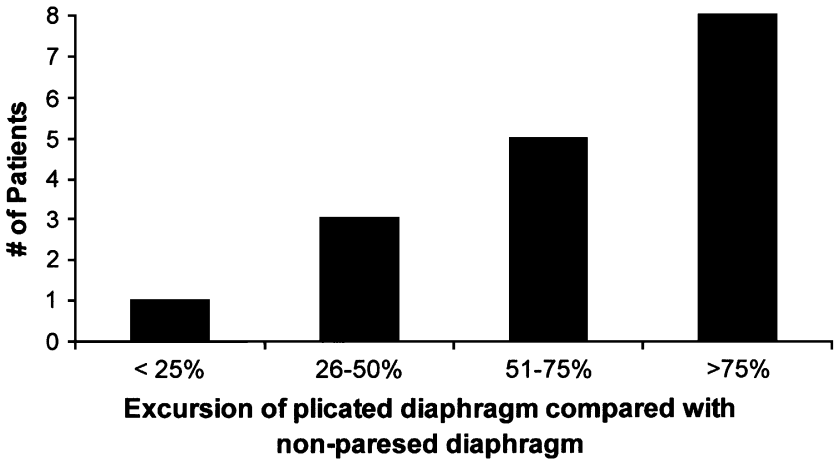

Figure 2. Distribution in return of diaphragm function after plication.

Ultrasound or fluoroscopy was used in 4 patients who underwent plication and demonstrated recovery of function.

In a smaller study of diaphragm paralysis after cardiac surgery, Joho-Arreola and colleagues ${ }^{1}$ noted an overall incidence of $5.4 \%$. The most common operations resulting in phrenic nerve injury were Fontan, Blalock-Taussig shunts, and arterial switch procedures. Follow-up included only chest x-ray noting a normal position of the plicated diaphragm in $86 \%$ at 1 month, which decreased to $62 \%$ at 1 year.

We have taken an aggressive approach to plication. Children who are unable to be weaned from mechanical ventilation or those who present with respiratory distress after extubation are examined for DP. A chest x-ray and fluoroscopy are used to diagnose diaphragm paralysis. We have routinely used fluoroscopy to establish the diagnosis at our institution. It is reliable and easy to perform and offers the ability to visualize both diaphragms simultaneously and compare their respective movements. The majority of cases in this series were diagnosed within 2 weeks of injury. After diagnosis, $86 \%$ of the patients $(n=46)$ were plicated within 3 days. This aggressive approach aids in preventing complications that can arise from long-term ventilatory support.

In our study, the majority of phrenic nerve injuries requiring diaphragm plication occurred on the left side. This high incidence of left-sided injuries may be related to extensive thymic resections in primary cases or the mobilization required for arch reconstructions. In the present study, the predominant surgery resulting in phrenic nerve injury requiring plication was the bidirectional Glenn procedure (left 6; right 11). The surprising number of left-sided injuries after the Glenn procedure is difficult to explain. Given that our study included only patients with clinically significant DP, we hypothesize that the respiratory compromise associated with DP may be more pronounced on the left side. This may be in part related to the combined mechanical compressive effects of the heart and the diaphragm.

The limitations of our study include the fact that we only reviewed patients with DP who required plication. Therefore, we do not have data on the true incidence of DP given that some patients did well without intervention. It is possible that surgical plication could limit the potential for return of diaphragm function. The present study was not designed to evaluate this because only patients requiring plication secondary to respiratory compromise were evaluated. This partly explains our extremely low incidence of plication after the Fontan procedure because these children are usually older than 2 years. ${ }^{15}$ Patients were studied at 1 time point after plication and compared with other patients studied at different time points. A future study that followed patients longitudinally over time would provide further insight into diaphragm recovery.

This study demonstrates that plication is an effective procedure for the treatment of DP. We have quantitated the return of diaphragm function over time. Our data suggest that diaphragm function improves over time after plication. The return of diaphragm function may be related to the

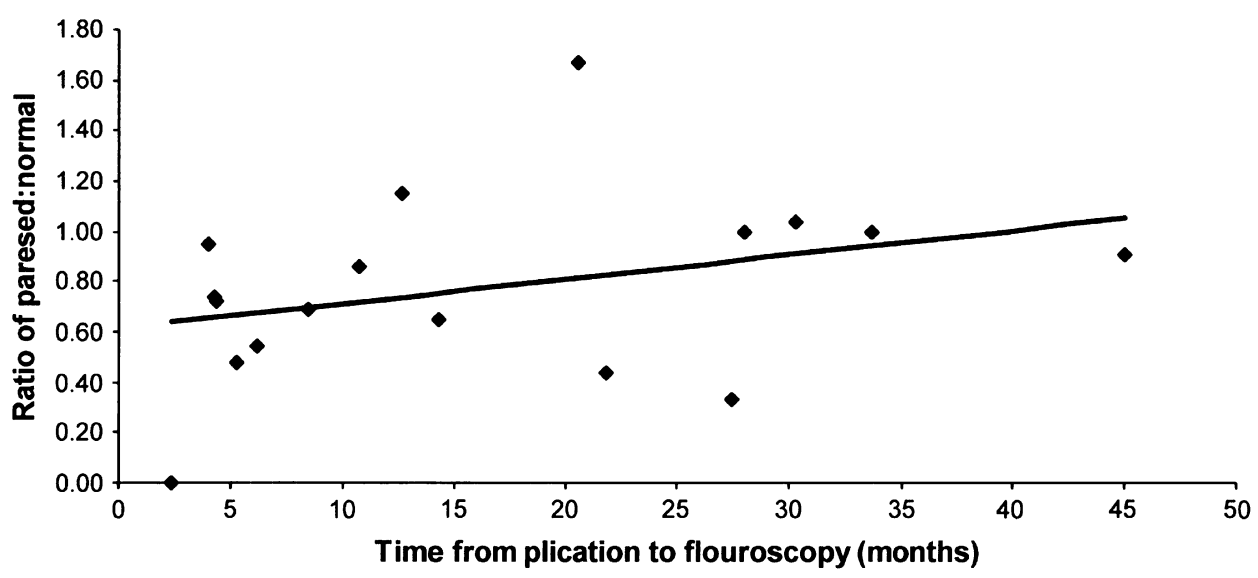

Figure 3. Diaphragm excursion ratio measured over time. 
nonpermanent nature of the injury thermal (hypothermia or cautery) or stretch. Given the return of function in almost all patients, as well as risks associated with adhesions surrounding the phrenic nerve, we do not advocate exploring the phrenic nerve at the time of plication. Somewhat unexpected were the data on 3 patients demonstrating orthograde diaphragm excursion of the plicated diaphragm in excess of the normal nonplicated diaphragm. It is possible that the nonplicated diaphragm that served as a control in these patients had some degree of paresis that was not clinically evident at the time of plication.

\section{Conclusions}

This study provides quantitative documentation of diaphragm function recovery. Diaphragmatic fluoroscopy 2.4 to 89.7 months postoperatively demonstrated return of function in $94 \%$ of patients studied.

\section{References}

1. Joho-Arreola AL, Bauersfeld U, Stauffer UG, Baenziger O, Bernet V. Incidence and treatment of diaphragmatic paralysis after cardiac surgery in children. Eur J Cardiothorac Surg. 2005;27:53-7.

2. de Leeuw M, Williams JM, Freedom RM, Williams WG, Shemie SD, McCrindle BW. Impact of diaphragmatic paralysis after cardiothoracic surgery in children. J Thorac Cardiovasc Surg. 1999;118:510-7.

3. van Onna IE, Metz R, Jekel L, Woolley Sr, van de Wal HJ. Post cardiac surgery phrenic nerve palsy: value of plication and potential for recovery. Eur J Cardiothorac Surg. 1998;14:179-84.
4. Shoemaker R, Palmer G, Brown JW, King H. Aggressive treatment of acquired phrenic nerve paralysis in infants and small children. Ann Thorac Surg. 1981;32:250-9.

5. Simansky DA, Payley M, Refaely Y, Yellin A. Diaphragm plication following phrenic nerve injury: a comparison of paediatric and adult patients. Thorax. 2002;57:613-6.

6. Stone KS, Brown JW, Canal DF, King H. Long-term fate of the diaphragm surgically plicated during infancy and early childhood. Ann Thorac Surg. 1987;44:62-5.

7. Watanabe T, Trusler GA, Williams WG, et al. Phrenic nerve paralysis after pediatric cardiac surgery. J Thorac Cardiovasc Surg. 1987;94: 383-8.

8. Langer JC, Filler RM, Coles J, Edmonds JF. Plication of the diaphragm for infants and young children with phrenic nerve palsy. J Pediatr Surg. 1988;23:749-51.

9. Tonz M, von Segesser LK, Mihaljevic T, Arbenz U, Stauffer UG, Turina MI. Clinical implications of phrenic nerve injury after pediatric surgery. J Pediatr Surg. 1996;31:1265-7.

10. Commare MC, Kurstjens SP, Barois A. Diaphragmatic paralysis in children: a review of 11 cases. Pediatr Pulmonol. 1994;18:187-93.

11. Muller NL, Bryan AC. Chest wall mechanics and respiratory muscles in infants. Pediatr Clin North Am. 1979;26:503-16.

12. Schwartz MZ, Filler RM. Plication of the diaphragm for symptomatic phrenic nerve paralysis. J Pediatr Surg. 1978;13:259-63.

13. Kizilcan F, Tanyel FC, Hicsonmez A, Buyukpamukcu N. The long-term results of diaphragmatic plication. J Pediatr Surg. 1993;28:42-4.

14. Tsugawa C, Kimura K, Hishijima E, Muraji T, Yamaguchi M. Diaphragmatic eventration in infants and children: is conservative treatment justified? J Pediatr Surg. 1997;32:1643-4.

15. Amin Z, McElhinney DB, Strawn JK, et al. Hemidiaphragm paralysis increases postoperative morbidity after a modified Fontan operation. J Thorac Cardiovasc Surg. 2001;122:856-62.

\section{Notice of Correction}

Ratcliffe MB, Guy TS. The effect of preoperative diastolic dysfunction on outcome after surgical ventricular remodeling. J Thorac Cardiovasc Surg. 2007;134:280-3.

The fourth sentence after the subheading "The Effect of Preoperative Diastolic Function on Outcome" should read as follows (with change marked in italic): "In all cases, the Starling relationship was depressed after partial ventriculectomy; however, the smallest decrement was associated with the highest diastolic stiffness. ${ }^{17,}$ 